\title{
A long way to go: minimizing the carbon footprint from anesthetic gases
}

\author{
Mary Hanna, MD, BHSc · Gregory L. Bryson, MD, FRCPC, MSc
}

Received: 7 March 2019/Accepted: 7 March 2019/Published online: 15 March 2019

(C) Canadian Anesthesiologists' Society 2019

Greenhouse gases (GHGs) are important contributors to global warming because they absorb and trap infrared radiation within the atmosphere. Anesthesiologists use potent GHGs - i.e., hydrofluorocarbons (sevoflurane and desflurane), chlorofluorocarbons (isoflurane), and nitrous oxide. Following their anesthetic use, these gases are scavenged from the anesthetic circuit and expelled into the atmosphere, where they can remain for decades. The global warming potential $\left(\mathrm{GWP}_{100}\right)$ compares the energy absorbed by 1 ton of a GHG relative to the energy absorbed by 1 ton of $\mathrm{CO}_{2}$ over a 100-year period, with a higher absorbance indicating a worse effect. ${ }^{1}$ With a $\mathrm{GWP}_{100}$ of 2540, desflurane absorbs far more energy than a comparable amount of $\mathrm{CO}_{2} .{ }^{2}$ Conversely, the $\mathrm{GWP}_{100}$ values for isoflurane, nitrous oxide, and sevoflurane are only 510,289 , and 130 , respectively. ${ }^{2}$

To illustrate the impact of anesthetic gases on the environment, we used calculations from Ryan and Nielsen to convert the $\mathrm{GWP}_{100}$ of each anesthetic gas (at 1 minimum alveolar concentration-hour and fresh gas flow rate of $1 \mathrm{~L} \cdot \mathrm{min}^{-1}$ ) to the grams of $\mathrm{CO}_{2}$ emitted per hour $\left(\mathrm{CO}_{2}\right.$ equivalent $\left.[\mathrm{CDE}]\right){ }^{3}$ The $\mathrm{CDE}$ was then converted to the distance (in kilometers) travelled assuming the average car emits $200 \mathrm{~g}$ of $\mathrm{CO}_{2}$ per kilometer. The distances displayed in the Figure document an imaginary road trip from Ottawa to Montreal, where:

One hour of $2 \%$ sevoflurane emits a CDE similar to that driving $6.5 \mathrm{~km}$;

One hour of $1.2 \%$ isoflurane emits a CDE similar to that driving $14 \mathrm{~km}$;

One hour of $60 \%$ nitrous oxide emits a CDE similar to that driving $95 \mathrm{~km}$;

One hour of $6 \%$ desflurane emits a CDE similar to that driving $320 \mathrm{~km}$ (a distance equivalent to driving to Montreal and half way back to Ottawa).

Desflurane's CDE is thus 50 times higher than that of sevoflurane. Anesthesiologists should consider the $\mathrm{GWP}_{100}$ in addition to the clinical and pharmacoeconomic factors when planning an anesthetic. As global citizens, it is our responsibility to find environmentally friendlier and more sustainable ways to practice anesthesia. 


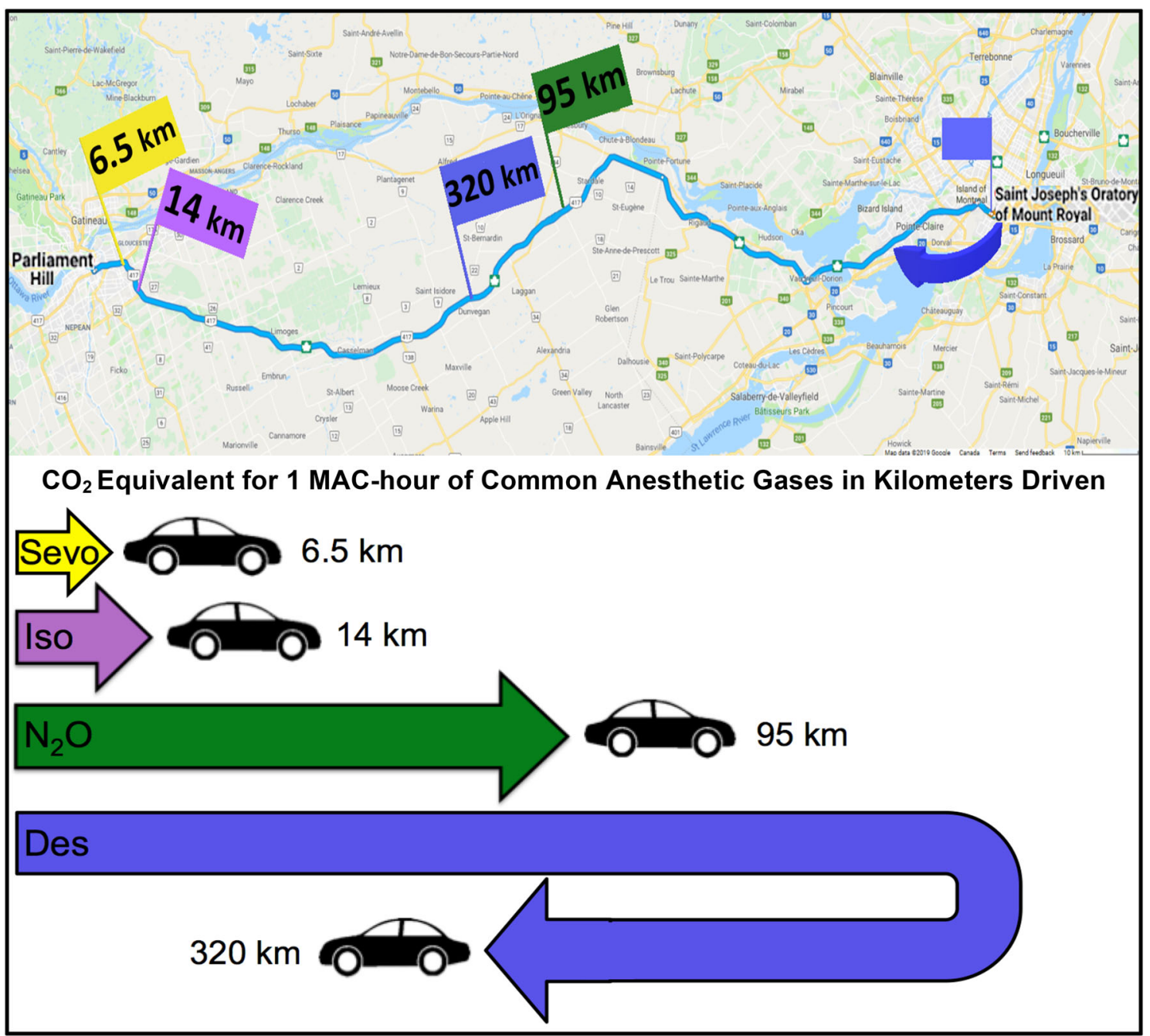

Figure Visual map of the $\mathrm{CO}_{2}$ equivalent for 1 MAC-hour of common anesthetic gases in kilometers driven. A route from Parliament Hill (111 Wellington St, Ottawa, ON, Canada) to Saint Joseph's Oratory of Mount Royal (3800 Queen Mary Road, Montreal, QC, Canada) was plotted using Google Maps. The total distance is $192 \mathrm{~km}$. The $\mathrm{CO}_{2}$ equivalent of travelling a distance (in kilometers) is

\section{Competing interests None declared.}

Editorial responsibility This submission was handled by Dr. Hilary P. Grocott, Editor-in-Chief, Canadian Journal of Anesthesia.

\section{References}

1. United States Environmental Protection Agency. Understanding Global Warming Potentials. Available from URL: https://www. calculated by assuming that a car emits $200 \mathrm{~g}$ of $\mathrm{CO}_{2}$ per kilometer. Desflurane's emission is equivalent to the distance driven to Montreal (small blue flag) and half way back to Ottawa (large blue flag). Desflurane $($ Des) $=$ blue; isoflurane (Iso) = purple; nitrous oxide $\left(\mathrm{N}_{2} \mathrm{O}\right)=$ green; sevoflurane $($ Sevo $)=$ yellow; MAC-hour $=1$ minimum alveolar concentration-hour

epa.gov/ghgemissions/understanding-global-warming-potentials (accessed March 2019).

2. Andersen MP, Nielsen $O$, Wallington T, Karpichev B, Sander S. Assessing the impact on global climate from general anesthetic gases. Anesth Analg 2012; 114: 1081-5.

3. Ryan S, Nielsen $C$. Global warming potential of inhaled anesthetics: application to clinical use. Anesth Analg 2010; 11: $92-8$.

Publisher's Note Springer Nature remains neutral with regard to jurisdictional claims in published maps and institutional affiliations. 